\title{
Determination of The Active Asiaticoside Content in Centella asiatica as Anti-Cellulite Agent
}

\author{
Dewi Sondari", Sri Budi Harmami, M. Ghozali, Ahmad Randy, \\ Athanasia Amanda S., Yan Irawan \\ Polymer Chemistry Group, Research Center for Chemistry \\ Indonesian Institute of Sciences (LIPI) \\ Kawasan Puspiptek Serpong, Tangerang 15314 - Indonesia
}

\begin{abstract}
Centella asiatica accumulates large quantities of pentacyclic triterpenoid saponins, collectively known as centelloids. These terpenoids include asiaticoside, centelloside, madecassoside, brahmoside, brahminoside, thankuniside, sceffoleoside, centellose, asiatic-, brahmic-, centellic- and madecassic acids. Preparations of $C$. asiatica are used in traditional and alternative medicine due to the wide spectrum of pharmacological activities associated with these secondary metabolites, such as anticellulite agent. Asiaticoside was found in Centella asiatica. In this present study, the asiaticoside was extracted using methanolic and ethanolic solvent. Determination of the asiaticoside content in the extract was conducted with High Performance Liquid Chromatography (HPLC), Thin Layer Chromatography (TLC), and Fourier Transform Infra Red (FTIR). Samples of $C$. asiatica used in this study came from three different plantation areas, Bogor, Lembang and Solo. Asiaticoside content in the methanolic extract from Bogor, Lembang, and Solo samples were 2.82\%; $2.68 \%$; and $2.8 \%$ respectively. Asiaticoside in ethanolic extract from Bogor, Lembang, and Solo samples were $2.79 \% ; 2.75 \%$; and $2.91 \%$ respectively. Two way ANOVA study showed that there was significant difference between types of solvent used in extraction and the asiaticoside content in the obtained extract, significant difference between varied plantation area and obtained asiaticoside content, and significant difference between interactions of different solvent with different plantation area.
\end{abstract}

Keywords: Centella asiatica, asiaticoside, anticellulite, medicine, metabolites

\section{INTRODUCTION}

Centella comprises some 50 species, inhabiting tropical and sub-tropical regions. This genus belongs to the plant family Apiaceae (Umbelliferae) and includes the most ubiquitous species Centella asiatica. This perennial creeper flourishes abundantly in moist areas and is a small, herbaceous annual plant of the subfamily Mackinlaya (Liu et al., 2003), previously included in Hydrocotyle (Brinkhaus et al., 2000), occurring in swampy areas of India, Sri Lanka, Madagascar, Africa, Australia (Schaneberg et al., 2003), China, Indonesia, Malaysia, Australia and Southern and Central Africa (Verma et al., 1999). The plant is clonally propagated by producing stolons that are characterized by long nodes and internodes which bear crowded cordate, obicular or reniform leaves and sessile flowers in simple umbels (Zheng and
Qin, 2007). Depending on environmental conditions, the form and shape of the $C$. asiatica plant can differ greatly (Adamson, 1950).

C. asiatica, also known as Gotu kola or Indian pennywort (Bruneton, 1995), is a medicinal plant that has probably been used since prehistoric times and has been reported to have been used for various medicinal and cosmetic purposes, thus becoming an important commercial product.

This plant is listed as a drug in the Indian Herbal Pharmacopoeia, the German Homeopathic Pharmacopoeia (GHP), the European Pharmacopoeia, and the Pharmacopoeia of the People's Republic of China (Schaneberg et al., 2003).

\footnotetext{
*Corresponding author e-mail : sondaridewi@yahoo.com
} 
According to World Health Organisation (WHO) monographs, Herbae Centellae should not contain less than $2 \%$ of the triterpene ester glycosides asiaticoside and madecassoside (WHO, 1999).

This study would determine the asiaticoside content in $C$. asiatica from Indonesian plantation area. Samples were collected from three different C. asiatica plantation area in Indonesia that are Bogor, Lembang, and Solo. Quantitative determination of asiaticoside content was conducted with high performance liquid chromatography (HPLC).

\section{MATERIALS AND METHODS}

Samples of Centella asiatica (L.) Urban were obtained from three plantation area in Indonesia: Solo, Lembang, and Bogor. Species analyses of C. asiatica were confirmed by Research Center for Biology, Indonesian Institute of Sciences. Ethanol, methanol, acetonitrile, aquades, chloroform, Silika GF254 were used as received.

\section{Extraction of C. asiatica}

Extraction of $C$. asiatica was studied using methanol $(70 \%)$ or ethanol $(70 \%)$. Sample from each plantation area were extracted. Extraction was conducted with maceration technique by immersing $400 \mathrm{~g}$ of $C$. asiatica sample in extraction solvent for 24 hours. Extract product was evaporated in rotary evaporator to obtain viscous extract.

\section{Qualitative determination of triterpenoid compound}

$5 \mathrm{mg}$ of extract and asiaticoside standard were mixed with $5 \mathrm{ml}$ methanol. The mixture was then heated in water bath for 2 minutes. These mixtures were cooled to room temperature, and filtered. Precipitate was washed with methanol to get $5 \mathrm{ml}$ filtrate. Sample and asiaticoside standard were spotted in Silica gel GF254 plate and were developed in chloroform:methanol (8:2). The plate was then sprayed with $\mathrm{H}_{2} \mathrm{SO}_{4} 10 \%$ (in methanol), and incubated in oven for 10 minutes at $110^{\circ} \mathrm{C}$. Spot was observed under $366 \mathrm{~nm}$ UV light to determine the $\mathrm{Rf}$ value of sample and asiaticoside standard.

\section{Solvent partition of $C$. asiaticoside extract}

Methanolic and ethanolic extract were further partitioned with dichloromethane-water
(1:1). Water phase from this dichloromethanewater were further partitioned with buthanol. Buthanol phase was separated, and the water phase was added with $100 \mathrm{ml}$ of $1 \mathrm{~N} \mathrm{NaOH}$. $\mathrm{NaOH}$ phase was separated and the water phase was added with aquadest until reaching $\mathrm{pH}$ of 7 . This water phase was concentrated with rotary evaporator until viscous extract was obtained. Obtained extract was passed to column chromatography with nbuthanol:ethyl acetate:water:ammonia (60:40:10:5) as the eluent.

\section{Quantitative analysis}

Quantitative determination of asiaticoside was conducted with high performance liquid chromatography (HPLC) using acetonitrile-water (70:30) as the mobile phase and silica column as the stationary phase, with flow rate of 1.0 $\mathrm{ml} /$ minute. Light detector in $221 \mathrm{~nm}$ was used to analyze asiaticoside. Series of asiaticoside standard was prepared and used to obtain calibration curve.

\section{RESULTS AND DISCUSSION}

\section{Qualitative determination of asiaticoside}

Sample from Bogor, Solo, and Lembang was sent to Herbarium Bogoriense to identify sample species. Identification result confirmed that samples from Bogor, Solo, and Lembang were Centella asiatica (L.) Urb. Samples were macerated in ethanol or methanol for 24 hours. This extract was further partitioned with dichloromethane-water (1:1). The water phase was futher partitioned with buthanol. Buthanol phase was separated, and the water phase was added with $\mathrm{NaOH}$. The water phase was added with aquadest until the $\mathrm{pH}$ reach 7. After further concentrated and passed to column chromatography with nbuthanol-ethyl acetate-water-ammonia (60:40:10:5) as the eluent, isolate was used for further qualitative and quantitative determination. Extract from different plantation area and varied extraction solvent was identified in thin layer chromatography (TLC). Identification with (TLC) was based on glycoside content in $C$. asiatica. Plate used was Silica gel GF254 developed with chloroform-methanol (8:2). To visualize the spot, $\mathrm{H}_{2} \mathrm{SO}_{4}(10 \%)$ was sprayed on the plate. Fig. 1 showed the resulted spot observed under UV light $(366 \mathrm{~nm})$. The spots detected from every samples and standard were clear and detectable. The $\mathrm{R}_{\mathrm{f}}$ value was shown in table I. Identification with TLC confirmed the presence of asiaticoside in 
methanolic extract from every plantation area, having same $R_{\mathrm{f}}$ value with asiaticoside standard reference $\left(R_{f}=0.2833\right)$. Meanwhile, ethanolic extract gave spot with different $R_{f}$ value with standard reference. This is due to different solubility of asiaticoside in ethanolic and methanolic. Qualitative determination of asiaticoside in the extract was also conducted by infrared spectroscopy. Fig. 2 show the infrared spectra of asiaticoside standard reference and extract sample.

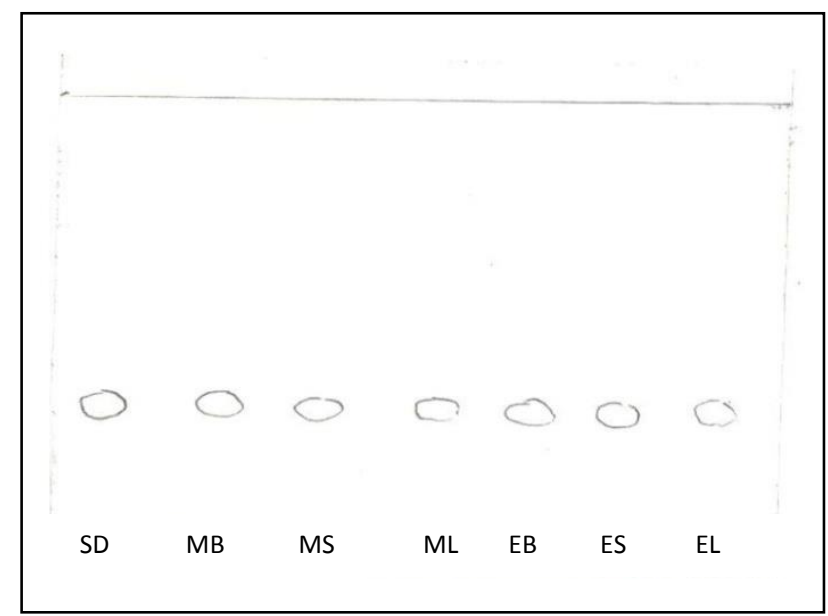

Figure I. Identification of asiaticoside with TLC

Table I. TLC Identification Result

\begin{tabular}{cc}
\hline $\mathbf{R f}$ & \multicolumn{1}{c}{ Spot } \\
\hline 0.2833 & SD: asiaticoside standard reference \\
0.2833 & MB: methanolic extract, Bogor plantation \\
0.2833 & MS: methanolic extract, Solo plantation \\
0.2833 & ML: methanolic extract, Lembang plantation \\
0.2666 & EB: ethanolic extract, Bogor plantation \\
0.2666 & ES: ethanolic extract, Solo plantation \\
0.2666 & EL: ethanolic extract, Lembang plantation \\
\hline
\end{tabular}

FTIR analysis of asiaticoside standard reference and methanolic extract from Lembang plantation

The FTIR spectra of asiaticoside standard reference and asiaticoside with methanolic extract from Lembang plantation are showed in Fig. 2. Comparing with the spectrum of asiaticoside standard reference (Fig. 2(a)), the absorption band at 918 and $970 \mathrm{~cm}^{-1}$ ascribed to $-\left(\mathrm{CH}_{2}\right)_{\mathrm{n}}, 1060 \mathrm{~cm}^{-}$ 1, $1641 \mathrm{~cm}^{-1}, 2908 \mathrm{~cm}^{-1}$, and $3273 \mathrm{~cm}^{-1}$ are ascribed to $-\mathrm{CO},-\mathrm{C}=\mathrm{O}$ of , $\mathrm{C}-\mathrm{H}$ and $\mathrm{R}-\mathrm{OH}$ of
Asiatic acid and Madecassid acid. As showed in (Fig. 2b), the absorption bands at $3275-3550 \mathrm{~cm}^{-1}$ ascribed to $\mathrm{C}-\mathrm{H}$, the absorption bands of $\mathrm{C}=\mathrm{O}$ $\left(1732 \mathrm{~cm}^{-1}\right)$ and absorption bands at $2906 \mathrm{~cm}^{-1}$ ascribed to $\mathrm{R}-\mathrm{OH}$, the absorption $1062 \mathrm{~cm}^{-1}$ and $653-680 \mathrm{~cm}^{-1}$ are ascribed to $\mathrm{C}-\mathrm{O}$ and $-\left(\mathrm{CH}_{2}\right)_{\mathrm{n}}$ bands. This information FTIR spectra of asiaticoside with extract methanolic from Lembang plantation suitable with asiaticoside standard reference. 

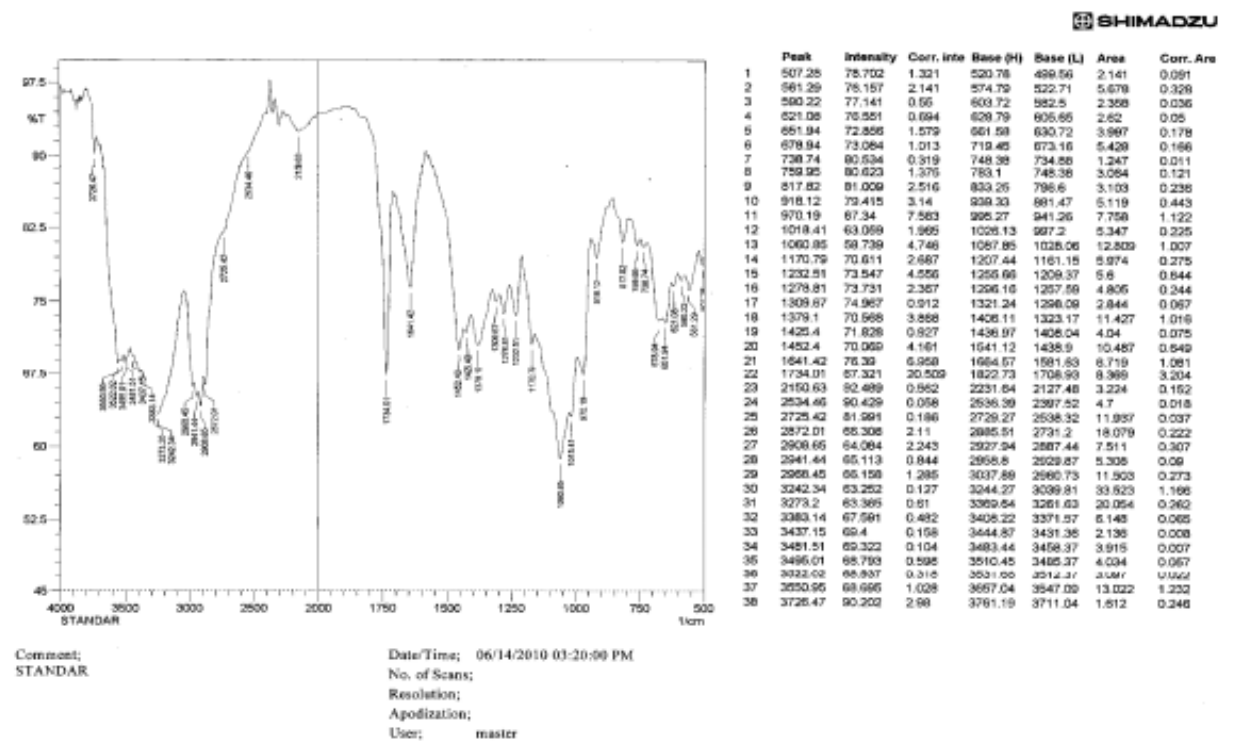

a) Standard
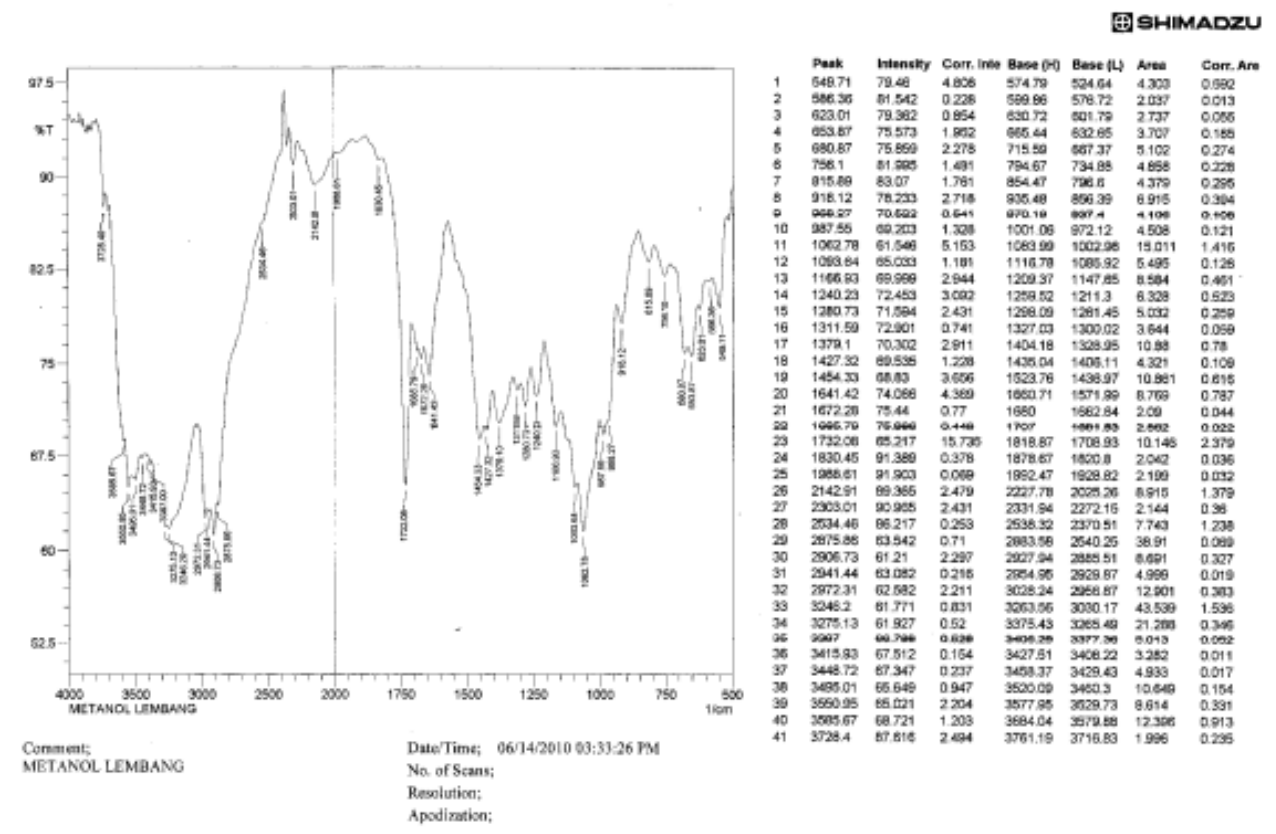

b) Methanolic extract, Lembang

Figure 2. FTIR spetra of a) asiaticoside standard reference and b) methanolic extract from Lembang plantation

\section{Quantitative determination of asiaticoside}

Quantitative determaination was conducted with HPLC. The HPLC detector used in this study was light detector. Prior to HPLC analysis, we determined the $\lambda_{\max }$ of asiaticoside standard reference and found that asiaticoside gave maximum absorbance in $221 \mathrm{~nm}$. We used this $\lambda_{\max }$ for HPLC analysis of asiaticoside.

HPLC analysis was conducted using stationary phase silica, mobile phase acetonitrile- 
water (70:30), and flow rate of $1.0 \mathrm{ml} / \mathrm{minute}$. System suitability test for this system resulted in standard deviation of $0.53 \%$. It meets the requirement from Farmakope Indonesia VI edition, which is minimal $2 \%$. Table II and III show the result of quantitative determination of asiaticoside content in ethanolic and methanolic extract.

Table II. Asiaticoside content of methanolic extract

\begin{tabular}{ccccc}
\hline Sample & $\begin{array}{c}\text { RT } \\
(\mathbf{m n t})\end{array}$ & $\begin{array}{c}\text { Area under } \\
\text { curve }\end{array}$ & Asiaticoside content (\%) & $\begin{array}{c}\text { Average } \\
\text { content } \\
(\%)\end{array}$ \\
\hline Bogor & 7.372 & 25981.89 & 2.8172 & 2.82 \\
& 7.378 & 25967.47 & 2.8157 & \\
Lembang & 7.374 & 24688.88 & 2.6740 & 2.68 \\
& 7.374 & 24773.79 & 2.6833 & \\
Solo & 7.376 & 25465.27 & 2.7788 & 2.80 \\
\hline
\end{tabular}

Table III. Asiaticoside content of ethanolic extract

\begin{tabular}{ccccc}
\hline Sample & $\begin{array}{c}\text { RT } \\
(\mathbf{m n t})\end{array}$ & $\begin{array}{c}\text { Area under } \\
\text { curve }\end{array}$ & Asiaticoside content (\%) & $\begin{array}{c}\text { Average } \\
\text { content } \\
(\%)\end{array}$ \\
\hline Bogor & 7.380 & 25773.79 & 2.7947 & 2.79 \\
& 7.380 & 25725.19 & 2.7894 & \\
Lembang & 7.371 & 25365.27 & 2.7473 & 2.75 \\
& 7.372 & 25327.66 & 2.7433 & \\
Solo & 7.373 & 26395.25 & 2.8803 & 2.91 \\
\hline
\end{tabular}

We can see that asiaticoside content between plantations areas were not differing largely. To see any significant difference of asiaticoside content between different plantation area and different extraction solvent, we conducted 2 ways ANOVA analysis. ANOVA analysis with $\alpha$ $=0.05$ showed that:

1. there was significant difference between types of solvent used in extraction and the asiaticoside content in the obtained extract,

2. there is significant difference between varied plantation area and obtained asiaticoside content, and
3. there is significant difference between interactions of different solvent with different plantation area.

\section{CONCLUSION}

Asiaticoside content in the methanolic extract from Bogor, Lembang, and Solo samples were $2.82 \% ; 2.68 \%$ and $2.8 \%$ respectively. Asiaticoside in ethanolic extract from Bogor, Lembang, and Solo samples were 2.79\%; 2.75\%; and $2.91 \%$ respectively. Two way ANOVA study showed that there was significant difference between types of solvent used in extraction and the asiaticoside content in the obtained extract, 
significant difference between varied plantation area and obtained asiaticoside content, and significant difference between interactions of different solvent with different plantation area.

\section{ACKNOWLEDGEMENT}

We acknowledge and thank Rahma from Pancasila Universty for her help and contribution in this work.

\section{REFERENCES}

Adamson, R.S., 1950, On some species of Centella. II. S, Afr. J. Bot., I 5, 93-95.

Brinkhaus, B., Linder, M., Schuppan, D. and Hahn, E.G., 2000, Chemical, pharmacological and clinical profile of the East African medicinal plant Centella asiatica, Phytomedicine, 7, 427-448.

Bruneton, J., 1995, Pharmacognosy, Phytochemistry, Medicinal Plants, 2nd ed.; Lavoisier Publishing, Paris, France.
Liu, M., van Wyk, B.E., and Tilney, P. M., 2003, A Taxonomic Evaluation of Fruit Structure in the Family Apiaceae, PhD thesis, University of Johannesburg, Auckland Park, South Africa.

Schaneberg, B.T., Mikell, J.R., Bedir, E. and Khan, I.A., 2003, An improved HPLC method for quantitive determination of six triterpenes in Centella asiatica extracts and commercial products. Pharmazie, 58, 38I-384.

Verma, R.K., Bhartariya, K.G., Gupta, M.M., and Kumar, S., 1999, Reverse-phase high performance liquid chromatography if asiaticoseide in Centella asiatica, Phytochem. Anal., 10, 191-193.

World Health Organisation, 1999, Herbae Centellae. In WHO Monographs on Selected Medicinal Plants; World Health Organisation: Geneva, Switzerland, Vol. I, pp.77-85.

Zheng, C.-J. and Qin, L.P., 2007, Chemical components of Centella asiatica and their bioactivities, Chin. J. Integr. Med, 5, 348$35 \mathrm{I}$. 